\title{
Mechanical Injury during Postharvest Handling of 'Solo' Papaya Fruit
}

\author{
Maria Eloisa G. Quintana' and Robert E. Paull ${ }^{2}$ \\ University of Hawaii at Manoa, 3190 Maile Way, Honolulu, HI 96822 \\ Additional index words. impact, abrasion, waxing, insect disinfestation, heat treatments, Carica papaya
}

\begin{abstract}
Solo' papaya (Carica papaya L.) fruit removed at different points from a commercial packing house showed that skin injury due to mechanical damage increased as fruit moved through the handling system. The occurrence of "green islands"-areas of skin that remain green and sunken when the fruit was fully ripe-apparently were induced by mechanical injury. Skin injury was seen in fruit samples in contact with the sides of field bins, but not in fruit taken from the center of the bins. Bruise-free fruit at different stages of ripeness (5\% to 50\% yellow) were dropped from heights of 0 to $100 \mathrm{~cm}$ onto a smooth steel plate to simulate drops and injury incurred during commercial handling. No skin injury occurred, although riper fruit showed internal injury when dropped from higher than $75 \mathrm{~cm}$. Fruit (10\% to 15\% yellow) dropped onto sandpaper from a height of $10 \mathrm{~cm}$ had skin injury symptoms similar to those seen on fruit from the commercial handling system. These results suggest that abrasion and puncture injury were more important than impact injury for papaya fruit. Heating fruit at $48 \mathrm{C}$ for $\approx 6$ hours or until fruit core temperature (FCT) reached $47.5 \mathrm{C}$ aggravated the severity of skin injury. Delays in the application of heat treatment from dropping did not reduce the severity of skin injury significantly, except for fruit heated 24 hours after dropping. Waxing fruit alleviated the severity of skin injury, whether applied before or after the heat treatment. Skin injury to papaya was caused by abrasion and puncture damage-not impact-and increased during postharvest handling of the fruit. The injury was associated mainly with fruit hitting the walls of wooden bins-bin liners may reduce this injury.
\end{abstract}

In 1990, fresh papaya fruit production in Hawaii totaled $\approx 26$ million $\mathrm{kg}$ (Souza, 1991). Hawaii is the major producer of papaya in the United States, and ships to the U.S. mainland and Japan. The East Coast of the United States also receives papaya shipments from Central and South America and the Caribbean (Cappellini et al., 1988). Inspection of papaya shipments on the New York market revealed several disorders, described as mechanical injury, physiological disorders, and postharvest disease (Cappellini et al., 1988); mechanical injury occurring in $14.8 \%$ of the shipments evaluated.

The response of most agricultural products to mechanical stress is time-dependent (Wang and Chang, 1970). The deformation caused to a fruit subjected to a static load depends not only on the magnitude of the applied load but also on the time period over which the load is applied. This time dependency of the mechanical behavior of fruit under stress is also related to fruit ripeness with time. Therefore, those physical properties that depend on the stage of maturity will also change with time. Wang and Chang (1970) reported that, as 'Solo' papaya fruit ripen, less deformation is required to initiate internal flesh damage. Their results also showed that the deformation rate of the fruit when damage occurs decreases continuously under constant plate loading. Further, the authors were able to establish a threshold for the amount of deformation that a fruit may undergo without suffering internal damage.

Received for publication 4 May 1992. Accepted for publication 18 Dec. 1992. Hawaii Institute of Tropical Agriculture and Human Resources Journal Series No. 3830. We appreciate the technical assistance provided by Ted Goo and Gail Uruu. Mention of a trade mark or proprietary product does not constitute a guarantee or warranty of a product by the Univ. of Hawaii, and does not imply its approval to the exclusion of other products that may also be suitable. This work was supported partially by the USDA/CSRS Special Grants Program in Tropical and Subtropical Agriculture 88-34153-3712. The cost of publishing this paper was defrayed in part by the payment of page charges. Under postal regulations, this paper therefore must be hereby marked advertisement solely to indicate this fact.

'Graduate student, Dept. of Horticulture.

${ }^{2}$ Professor, Dept. of Plant Molecular Physiology.
Ripe papaya fruit frequently show sunken skin areas that fail to degreen. These unsightly fruit blemishes are of concern to shippers and are referred to as "green islands." This skin injury has been observed to be associated with broken skin; however, its occurrence does not seem to be aggravated by the presence of latex seeping from the wound. We do not know at what point in the postharvest handling system of papayas that this skin injury occurred. We hypothesized that the insect quarantine treatments the fruit undergo before shipment may have aggravated this skin injury. Except for the research of Wang and Chang (1970) on deformation of 'Solo' papaya fruit and of Kumar and Wang (1971) on the response of papaya fruit to dynamic loading, there have been no published works on mechanical injury in papaya to the best of our knowledge. This research was undertaken to determine where along the packing line injury occurred in a large commercial packing house and the conditions that would affect the injury in a laboratory.

\section{Materials and Methods}

'Kapoho Solo' and 'Sunset Solo' papaya fruit were obtained from Puna and Poamoho Experiment Farm (central Oahu), Hawaii, respectively. 'Kapoho Solo' fruit were used in the evaluation of a commercial packing house, while 'Sunset Solo' fruit were used in subsequent laboratory experiments. The stage of fruit ripeness used was selected according to the objectives of individual experiments. The fruits were obtained by partitioning a population at one time according to ripeness. In most experiments, 10 fruit were used for each treatment. Unless otherwise stated, after each treatment, fruit were dipped in $650 \mathrm{ppm}$ a.i. thiabendazole (Mertect 340-F, Merck \& Co., Rahway, N.J.) for $5 \mathrm{~s}$ to control fungal decay (Couey and Farias, 1979). Fruit were air-dried before ripening at $25 \mathrm{C}$. Dropping experiments were done by using an apparatus that held the fruit by vacuum at the desired equatorial orientation and height. No obvious injury was caused by this vacuum apparatus. Fruit were dropped onto a smooth steel plate and caught after one bounce.

Fruit evaluation. Observations depended on the objectives of individual experiments. Fruit were evaluated for the following 
characteristics: 1) initial and final skin colors were expressed as percent of yellow skin of the whole surface area; 2) flesh color was expressed as percentage of full-ripened color with normal color development $(0 \%$ to $100 \%)$ and on a scale for overripe fruit $(101 \%$ to $140 \%$ ) with water-soaked flesh; 3) firmness was expressed in Newtons; measured with an AccuForce Cadet Force Gage (Ametek, Mansfield and Green Div., Largo, Fla.) registering the force required to push a 1.5 -cm-diameter plunger $2 \mathrm{~mm}$ into the flesh, with skin intact; 4) shriveling was estimated subjectively on a scale of $0=$ none, $1=$ slight, $2=$ moderate, and $3=$ severe, and 5) skin injury was expressed as percent of fruit surface area affected-severity of injury was estimated subjectively on a scale from $0=$ none, $1=$ light green impact area, $2=$ medium green, and $3=$ dark green.

Fruit injury in a commercial postharvest handling system. Commercial processing of papaya in a packing house on the island of Hawaii was observed twice (Sept. 1989 and 1990) during operation. Fruit quality was evaluated on fruit removed at six points in the handling system: 1) at harvest-fruit were taken from the denim bags carried by the fruit pickers before fruit were transferred to a field bin; 2) upon arrival at the packing house when fruit were unloaded by floating in water-fruit were sampled while still in the water (before culling); 3) after fruit were dropped into $1200 \times 1200$ $\times 600$-mm-deep bins (after culling); 4) floated in water out of bin (before waxing); fruit were sampled while still in the water; 5) after drop onto packing tables (after waxing); and 6) from packed carton after transfer onto conveyor. The last sampling point was added during the second trial. Twenty fruit were removed at each point and divided into two lots. Before shipment to the laboratory in Honolulu, 10 fruit were inoculated with spores and hyphae of Rhizopus stolonifer (Ehrenb.) Lind without injuring the fruit. This pathogen requires cuticle damage to invade fruit because it lacks the necessary cutinase to penetrate the epidermal tissue (Alvarez and Nishijima, 1987). Fruit were wrapped individually in Styrofoam sheets and packed in a single layer with crumpled newspaper in cardboard boxes for the return by air to the laboratory in Honolulu. All fruit (inoculated and noninoculated) were allowed to ripen at $25 \mathrm{C}$. In the second trial, fruit were rinsed with tap water after removal from the chlorinated water in the dump tanks.

Bruising effects. Fruit were harvested carefully, wrapped individually in Styrofoam protective sleeves, and returned to the laboratory in cardboard boxes. The protective sleeves were removed after sorting fruit into various stages of ripeness: $5 \%$ to $10 \%, 25 \%$ to $30 \%$, and $40 \%$ to $50 \%$ peel yellowing before the fruit were dropped. Fruit were dropped from heights of 0 to $100 \mathrm{~cm}$. This experiment was done in three (5\% to $10 \%$ yellow, $25 \%$ to $30 \%$ yellow, $40 \%$ to $50 \%$ yellow) parts, with a different stage of fruit ripeness being done in each part.

Sandpaper was used to cause abrasion/puncture injury as it is available in uniform sheets with diverse degrees of grittiness. The grades of sandpaper initially tested were: 220 mesh - very fine, 150 mesh-fine, 100 mesh-medium, 50 mesh-coarse, and 36 meshvery coarse. In subsequent experiments, 150 mesh sandpaper was used routinely, as it inflicted a more-uniform skin injury at the fruit impact area. Fruit with $10 \%$ to $15 \%$ skin yellowing were dropped from a height of 10,50 , or $100 \mathrm{~cm}$ onto a steel plate covered with 150 -mesh sandpaper. Other ripeness stages $(5 \%$ to $10 \%, 10 \%$ to $15 \%, 25 \%$ to $30 \%, 40 \%$ to $50 \%, 70 \%$ to $80 \%$, and $90 \%$ to $100 \%$ yellow) were used as required in other tests.

Role of latex and abrasion injury. Fruit that were not dropped were wiped in spots with latex collected recently from other fruits. On dropped fruit, the latex was left to dry or washed off with copious amounts of tap water either immediately or $1 \mathrm{~h}$ after the fruit had been dropped.
Duration between dropping and heating. At various times $(0,6$, $12,24,36$ and $48 \mathrm{~h}$ ) after dropping, fruit were hot air-treated at $48 \mathrm{C}$ for $\approx 6 \mathrm{~h}$ or until the fruit core temperature (FCT) reached $47.5 \mathrm{C}$ (Armstrong et al., 1989). Heating was initiated in all treatments at the same time. Relative humidity during treatment was held between $50 \%$ to $60 \%$. After the heat treatment, the fruit were cooled immediately by a cold water shower until FCTs reached $<30 \mathrm{C}(\approx 45 \mathrm{~min})$ and then were ripened at $25 \mathrm{C}$.

Fruit waxing and heat. After dropping, fruit were waxed and then heated and cooled as above. Two waxes were used: FMC-819, a carnauba-based wax, and FMC-820, a polyethylene-paraffin wax (FMC Corp., Riverside Calif.). A 1 wax : 3 water ratio was used, resulting in a solution with $2 \%$ to $3 \%(\mathrm{w} / \mathrm{v})$ solids. In a supplementary experiment, fruit were waxed with FMC-819 (1:3) only, either before or after the heat treatment.

Respiration rate and ethylene production. Eighteen fruits at $10 \%$ yellow were used to determine respiration rate and ethylene production. Each fruit was dropped individually on its equator from a height of $10 \mathrm{~cm}$ onto a smooth steel plate or onto a steel plate covered with sandpaper. Respiration rate and ethylene production were determined after zero, one, two, four, and eight drops. Fruit were sealed individually daily for $1 \mathrm{~h}$ in $\approx 2500-\mathrm{ml}$ containers. The headspace gas was mixed by pumping with a $10-\mathrm{ml}$ syringe before taking two 1-ml gas samples from each container. Carbon dioxide was measured using an infrared $\mathrm{CO}_{2}$ gas analyzer (Clegg et al., 1978) and ethylene production with a gas chromatograph fitted with an alumina column and photoionization detector (Bassi and Spencer, 1985).

\section{Results and Discussion}

Fruit injury during commercial handling. Mechanical injury to papaya fruit taken randomly from different points along the handling system and ripened at $25 \mathrm{C}$ was manifested as green sunken areas on the skin of yellow ripe fruit. Incidence of skin injury increased significantly as the fruit moved through the handling system (Table 1). Inoculating fruit within hours of removal from the handling system with $R$. stolonifer did not affect skin injury, disease incidence, and disease severity significantly (data not shown).

The greatest increase in skin injury was seen between point 3 (after culling) and point 6 (after packing), with skin injury severity increasing nearly four-fold (Table 1). During the time of this study, Timm and Brown $(1989,1991)$ evaluated the same packing line using an instrumented sphere (IS) and showed that samples taken for this experiment recorded the highest impacts at the following transfer points in order of average impact force-at the culling

Table 1. Effect of taking fruit at different sampling points in a commercial papaya packing house on the amount of skin injury on the fruit surface. Fruit were evaluated at full ripeness after storage at $25 \mathrm{C}$.

\begin{tabular}{lc}
\hline \hline Sampling points in the handling system & Skin injury \\
\hline At harvest & $8 \mathrm{a}^{y}$ \\
Before culling & $11 \mathrm{a}$ \\
After culling & $18 \mathrm{ab}$ \\
Before waxing & $33 \mathrm{bc}$ \\
After waxing & $30 \mathrm{bc}$ \\
After packing & $40 \mathrm{c}$
\end{tabular}

${ }^{\mathrm{z}}$ Expressed as percent fruit surface area affected.

'Data were analyzed using the Waller-Duncan K-ratio $t$-test. Means within a column followed by the same letter are not significantly different at $P \leq 0.05(\mathrm{n}=10)$. 
line: 1) roll conveyor after the culling station; 2) lowerator into bin; and on the packing line: 3) transfer belt; 4) belt to brusher; and 5) onto packing table. Transfer point 2 (lowerator into bin) corresponds to point 3 (after culling) in this study, where skin injury increased $\approx 50 \%$ from the previous step. At this point, fruit were lowered into the bin by holding the fruit between a pair of looped belts. Fruit-to-fruit impact was reduced by using a padded horizontal plate under the lowerator outlet. Fruit hitting the sides or bottom of the bin were probably the cause of the hard impacts measured at 60 to $70 \times \mathrm{g}$ by Timm and Brown (1991). This increase could indicate that cumulative injury occurs with each impact or more that damage occurs at certain points in the handling chain. 'Golden Delicious' apples (Malus domestica Borkh.) sampled from packing lines showed impact bruise, cut, and puncture injury that was cumulative (Brown et al., 1989). Similarly, in a citrus packing line, injury detected by using a dilute solution of 2,3,5-triphenyltetrazolium chloride to outline each lesion in red, increased as fruits moved from one handling operation to another (Eaks, 1961).

Impact injury. Hard impacts in the range of 50 to $100 \times \mathrm{g}$ were initially thought to cause the skin injury, as only low-level impacts are recorded between fruit (Timm and Brown, 1989). Impacts found in papaya fruit handled commercially was duplicated by dropping fruits onto a smooth steel plate. However, no definite trend was seen in skin injury of dropped fruit within each fruit ripeness stage (data not shown). The injury seen in fruit dropped from different heights onto a smooth steel plate was not similar to the skin injury on fruit taken off the commercial packing line. Skin injury due to impact on the smooth steel plate was minor (slight shriveling), with the fruit skin apparently remaining unbroken. At the full-ripe stage, internal injury was seen only in $40 \%$ to $50 \%$ yellow fruits dropped from $100 \mathrm{~cm}$ (data not shown). This injury was manifested as water-soaked tissue that subtended the point of impact, a typical symptom of an impact bruise seen in other fruit. Occasionally, a thin line of water-soaked flesh tissue was also seen on the opposite side of the fruit from the point of impact. This pattern suggested that mature green papaya fruits were very elastic and could withstand a drop from $100 \mathrm{~cm}$ until reaching the $40 \%$ to $50 \%$ yellow stage of ripeness. Because elasticity is the capacity of the material to withstand elastic or recoverable deformation, the results suggest that the resistance to impact bruising and injury declines as papaya fruit mature. This assumption agrees with the finding of a three-fold reduction in the modulus of elasticity in Malaysian papaya from the mature to the overripe stage (Zohadie, 1982). Similar results have been reported for 'Babygold Five' peaches [Prunus persica (L.) Batsch.], where the modulus of elasticity decreases with increasing fruit maturity (Genge et al., 1977). Further, more-mature 'Red Globe' peaches have greater susceptibility to bruising and have larger bruise volumes than the less-mature fruit (Hung and Prussia, 1989). Fruit ripening, measured as change in fruit firmness, was not affected significantly in dropped fruit (data not shown).

Abrasion/puncture injury. Skin injury was seen in all fruits dropped onto all grades of sandpaper (220 to 36 mesh). This skin injury was similar to the symptoms seen in fruits sampled during commercial handling. The severity of skin injury in the impact area increased significantly (Table 2) as the sandpaper particle size decreased. Fruit dropped onto fine sandpaper would have more skin penetration per unit area compared with fruit dropped on coarse sandpaper; hence, the higher severity of skin injury.

Fruits from the side of the commercial field bin had more skin injury than fruits taken from the center of the bin; this difference was significant at $P \leq 0.10$ (data not shown). Contact with the plywood bin wall apparently caused skin injury by abrasion and
Table 2. Effect of dropping $10 \%$ to $15 \%$ yellow fruit from $10 \mathrm{~cm}$ onto various degrees of fineness of sandpaper on the severity of skin injury. Fruit were evaluated at full ripeness following storage at $25 \mathrm{C}$.

\begin{tabular}{lc}
\hline Fineness of sandpaper (mesh) & Severity of skin injury $^{2}$ \\
\hline Control & $0 \mathrm{a}^{\mathrm{y}}$ \\
220 (very fine) & $1.8 \mathrm{c}$ \\
150 & $2.0 \mathrm{c}$ \\
100 & $1.4 \mathrm{~b}$ \\
50 & $1.4 \mathrm{~b}$ \\
36 (very coarse) & $1.2 \mathrm{~b}$ \\
Analysis of variance & $* * *$
\end{tabular}

$\overline{{ }^{\mathrm{z}} \text { Evaluated the color of the skin injury using the scale: } 0=\text { none, } 1=\text { light }}$ green, 2 = medium green, and $3=$ dark green .

'Data were analyzed using the Waller-Duncan K-ratio $t$-test. Means followed by the same letter are not significantly different at $P \leq 0.05(\mathrm{n}=$ 10).

***Significant at $P \leq 0.001$ level.

puncture rather than by impact. The plywood field bins are not always smooth and the sides and bottom become rougher with use due to fiber splitting and damage. Lemons [Citrus limon (L.) Burm.] taken off a packing line had surface lesions due to abrasion injury when fruits came in contact with rough surfaces of boxes and equipment (Eaks, 1961). This is in contrast with impact, vibration, and excessive conveyor speeds contributing to fruit damage in oranges [Citrus sinensis (L.) Osh.] (Eaks, 1961) and 'Golden Delicious' apples (Brown et al., 1989).

The severity of skin injury was significantly lower when fruit were dropped at the $40 \%$ to $50 \%$ yellow stage than at the $5 \%$ to $10 \%$ stage (Table 3). A maximal level of total chlorophylls $(62.4 \mu \mathrm{g} \cdot \mathrm{cm}-$ $\left.{ }^{2}\right)$ occurs at the mature-green stage and declines as ripening progresses (Sanxter, 1989). Therefore, fruit with less chlorophyll in the peel or with active chlorophyll degradation at the time of dropping showed less skin injury development than green fruit.

Role of latex and skin injury. Generally, less latex exuded from the skin laticifers in riper fruit compared with greener fruit following injury (Becker, 1958). No latex was obtained from fully ripe fruit (Skelton, 1969). Latex exudation did not seem to be one of the factors affecting the severity of skin injury in this study, as wiping or washing the impact zone with tap water did not reduce the severity of skin injury (data not shown). However, latex released from ruptured laticifers under the epidermis could have played a role in the development of skin injury.

Duration between dropping and heating. Postharvest disinfestation for fruit flies requires heat treatment of the fruit at $48 \mathrm{C}$ before grading and packing. These heat treatments lead occasionally to a failure of the mesocarp to soften without adversely affecting other changes that occur during ripening (Paull

Table 3. Severity of skin injury in papaya fruit at different stages of fruit ripeness dropped from $10 \mathrm{~cm}$ onto a smooth steel plate covered with 150 mesh sandpaper. Fruit were evaluated at full ripeness following storage at $25 \mathrm{C}$.

\begin{tabular}{lc}
\hline Peel color (\% yellow) & Severity of skin injury, \\
\hline $5-10$ & $2.5 \mathrm{a}$ \\
$10-15$ & $2.1 \mathrm{ab}$ \\
$25-30$ & $1.8 \mathrm{ab}$ \\
$40-50$ & $1.6 \mathrm{~b}$
\end{tabular}

${ }^{2}$ Data were analyzed using the Waller-Duncan K-ratio $t$-test. Means followed by the same letter are not significantly different at $P \leq 0.05(\mathrm{n}=$ $10)$.

${ }^{y}$ Evaluated the color of skin injury using the scale: $0=$ none, $1=$ light green, 2 = medium green, and $3=$ dark green. 
Table 4. Effect of delays in heat treatment on firmness, flesh color, and severity of skin injury of $10 \%$ to $15 \%$ yellow papaya fruit ${ }^{2}$ heated after being dropped from $10 \mathrm{~cm}$ onto a smooth steel plate covered with 150 mesh sandpaper.

\begin{tabular}{lccc}
\hline \hline Delay (h) & $\begin{array}{c}\text { Firmness } \\
(\mathrm{N})^{\mathrm{y}}\end{array}$ & $\begin{array}{c}\text { Flesh } \\
\text { color }^{\mathrm{y}}\end{array}$ & $\begin{array}{c}\text { Severity of } \\
\text { skin injury }\end{array}$ \\
\hline Control (dropped without heat) & $33 \mathrm{a}$ & $98 \mathrm{~b}$ & $1.3 \mathrm{a}$ \\
0 (dropped, immediately heated) & $146 \mathrm{~d}$ & $86 \mathrm{a}$ & $2.2 \mathrm{~b}$ \\
6 & $84 \mathrm{bc}$ & $86 \mathrm{a}$ & $2.3 \mathrm{~b}$ \\
12 & $99 \mathrm{bc}$ & $91 \mathrm{ab}$ & $2.5 \mathrm{~b}$ \\
24 & $70 \mathrm{ab}$ & $86 \mathrm{a}$ & $1.6 \mathrm{a}$ \\
36 & $114 \mathrm{~cd}$ & $92 \mathrm{ab}$ & $2.5 \mathrm{~b}$ \\
48 & $111 \mathrm{~cd}$ & $90 \mathrm{ab}$ & $2.2 \mathrm{~b}$ \\
\hline
\end{tabular}

$\overline{{ }^{z} \text { Fruit were heated at } 48 \mathrm{C} \text { for } \approx 6 \mathrm{~h} \text { or until the fruit core temperature (FCT) }}$ reached $47.5 \mathrm{C}$, after which fruit were cooled down quickly with a cold water shower until FCT was $<30 \mathrm{C}$. Fruit were evaluated at full ripeness after storage at $25 \mathrm{C}$.

'Data were analyzed using the Waller-Duncan K-ratio $t$-test. Means within a column followed by the same letter are not significantly different at $P \leq 0.05(\mathrm{n}=10)$.

${ }^{\mathrm{x}}$ Evaluated the color of skin injury using the scale: $0=$ none, $1=$ light green, 2 = medium green, and $3=$ dark green.

and Chen, 1990). Heating fruit immediately after dropping or several hours later, however, aggravated the severity of skin injury equally compared to unheated fruit (Table 4). It is possible that heating the fruits further suppressed the production of ethylene (Maxie et al., 1974) in the injured cells within the injured area. This injury might have inhibited chlorophyll breakdown in the injured area. However, the severity of skin injury was less in fruits heated $24 \mathrm{~h}$ after dropping than in fruit heated 36 and $48 \mathrm{~h}$ after being dropped (Table 4); this difference was observed in other similar trials. The reason for this difference is unknown, although significant changes in peel color started $24 \mathrm{~h}$ after dropping.

Fruit waxing. Waxing papaya fruits reduced weight loss by $14 \%$ to $40 \%$ (Paull and Chen, 1989). Waxing resulted in significantly firmer fruit, with lower weight loss, less shriveling, and less severe skin injury compared to the unwaxed controls dropped 10 $\mathrm{cm}$ onto a smooth steel plate covered with 150-mesh sandpaper (Table 5). Fruit waxed with FMC-819 had slightly less weight loss compared with fruit waxed with FMC-820; hence, FMC-819 was used in subsequent experiments. The alleviation of the severity of

Table 5. Effect of waxing on shriveling, severity of skin injury, and percent weight loss in papaya fruit $^{\mathrm{z}}$ waxed and heated after being dropped from $10 \mathrm{~cm}$ onto a smooth steel plate covered with 150-mesh sandpaper.

\begin{tabular}{lcccc}
\hline \hline Wax & Shriveling $^{\mathrm{y}, \mathrm{x}}$ & ${\text { Firmness }(\mathrm{N})^{\mathrm{y}}}^{\mathrm{s}}$ & $\begin{array}{c}\text { Severity of } \\
\text { skin injury }\end{array}$ & $\begin{array}{c}\text { Weight } \\
\text { loss }^{\mathrm{y}}(\%)\end{array}$ \\
\hline None & $2.1 \mathrm{a}$ & $56 \mathrm{~b}$ & $1.4 \mathrm{a}$ & $8.3 \mathrm{a}$ \\
FMC-819 & $0.1 \mathrm{~b}$ & $93 \mathrm{a}$ & $0.8 \mathrm{~b}$ & $3.3 \mathrm{~b}$ \\
FMC-820 & $0.1 \mathrm{~b}$ & $91 \mathrm{a}$ & $0.6 \mathrm{~b}$ & $3.9 \mathrm{~b}$ \\
ANOVA & $* * *$ & $* *$ & $*$ & $* * *$
\end{tabular}

${ }^{\mathrm{z}}$ Fruit were heated at $48 \mathrm{C}$ for $\approx 6 \mathrm{~h}$ or until FCT reached $47.5 \mathrm{C}$, after which fruit were cooled down quickly with a cold water shower until FCT was $<30 \mathrm{C}$. Fruit were evaluated at full ripeness after storage at $25 \mathrm{C}$.

y Data were analyzed using the Waller-Duncan K-ratio $t$-test. Means within a column followed by the same letter are not significantly different at $P \leq 0.05(\mathrm{n}=36)$.

'Evaluated using the scale: $0=$ none, $1=$ slight, $2=$ moderate, $3=$ severe. wEvaluated the color of the skin injury using the scale: $0=$ none, $1=$ light green, $2=$ medium green, and $3=$ dark green.

${ }_{*}^{* * *, * * *}$ Significant at $P \leq 0.05,0.01$, and 0.001 , respectively. skin injury by fruit waxing was possibly due to reduced weight loss. Papaya fruit peel from an injured area had a lower percent fresh weight than skin from a noninjured area with the same surface area (data not shown). The relative humidity during heating was maintained between $50 \%$ to $60 \%$ in these tests. Under these conditions, no difference was found between waxing before or after the heat treatment (data not shown).

Respiration rate and ethylene production. Unlike in most fruits (Eaks, 1961; McGlasson and Pratt, 1964; Robitaille and Janick, 1973; MacLeod et al., 1976; Hoffman and Yang, 1982; Burton and Schulte-Pason, 1987), impact and abrasion injury in papaya fruits did not increase the respiration rate or ethylene production during ripening significantly (data not shown). Increasing the number of impact drops from one to eight onto a smooth steel plate or 150mesh sandpaper also did not increase the respiration rate or ethylene production of fruits during subsequent ripening at $25 \mathrm{C}$ significantly (data not shown). One possible explanation was that the increase in respiration rate and ethylene production by the injured area was too small to be measured relative to the overall fruit respiration rate and ethylene production. Also, cells in the abraded areas may have been ruptured by the abrasion and no longer capable of ethylene production. Another possible explanation was that the impact force was spread throughout the whole fruit and thus did not exceed cell burst strength as occurs in apples (Brusewitz and Bartsch, 1989; Roudot et al., 1991). No stimulation of ethylene evolution was reported by Wade and Bain (1980) following impact bruising of sweet cherry (Prunus aviuum (L.) L.] fruit.

In this study, mechanical skin injury was evaluated as skin injury that we believed to be what Cappellini et al. (1988) referred to as "bruise damage" and "sunken discoloration." In the commercial postharvest handling system for 'Solo' papaya, fruit injury occurred at certain points in the handling system primarily associated with contact with the field bin walls. Skin injury was determined to be caused by abrasion/puncture injury and not by impact bruises. The heat treatments for fruit fly disinfestation aggravated the severity of skin injury; waxing either prior to or after heat treatment reduced the severity of skin injury. The physiological explanation for the abraded area remaining green is unknown. Further research should be directed at determining whether the cells in the abraded area are viable and capable of respiration and ethylene production. Plastic bin liners or plastic bins should be tested as to their effectiveness in reducing skin injury.

\section{Literature Cited}

Alvarez, A.M. and W.T. Nishijima. 1987. Postharvest diseases of papaya. Plant Dis. 71:68 1-686.

Armstrong, J.W., J.D. Hansen, B.K.S. Hu, and S.A. Brown. 1989. High-temperature, forced air quarantine treatment for papaya infested with Tephritid fruit flies (Diptera:Tephritidae). J. Econ. Entomol. 82:1667-1674.

Bassi, P.K. and M.S. Spencer. 1985. Comparative evaluation of photoionization and flame ionization detectors for ethylene analysis. Plant, Cell \& Environ. 8:161-165.

Becker, S. 1958. The production of papain-an agricultural industry for tropical America. Econ. Bot. 12:62-79.

Brown, G.K., C.L. Burton, S.A. Sargent, N.L. Schulte-Pason, E.J. Timm, and D.E. Marshall. 1989. Assessment of apple damage on packing lines. Applied Eng. Agr. 5:475-484.

Brusewitz, G.H. and J.A. Bartsch. 1989. Impact parameters related to postharvest bruising of apples. Trans. ASAE 32:953-957.

Burton, C.L. and N.L. Schulte-Pason. 1987. Carbon dioxide as an indicator of fruit impact damage. HortScience 22:281-282.

Cappellini, R.A., M.J. Ceponis, and G.W. Lightner. 1988. Disorders in 
apricot and papaya shipments to the New York market 1972-1985 Plant Dis. 72:366-368

Clegg, M.D., C.Y. Sullivan, and J.D. Eastin. 1978. A sensitive technique for the rapid measurement of carbon dioxide concentrations. Plant Physiol. 62:924-926.

Couey, H.M. and G. Farias. 1979. Control of postharvest decay of papaya. HortScience 14:719-721.

Eaks, I.L. 1961. Techniques to evaluate injury to citrus fruit from handling practices. Proc. Amer. Soc. Hort. Sci. 78:190-196.

Genge, R.A., W.K. Bilanski, and D.R. Menzies. 1977. The physicalbiological properties of Babygold Five peaches as related to mechanical harvesting. Trans. ASAE 20:772-775.

Greenland, A.J. and D.H. Lewis. 1984. Amines in barley leaves infected by brown rust and their possible relevance to formation of 'green islands'. New Phytol. 96:283-291.

Hoffman, N.E. and S.F. Yang. 1982. Enhancement of wound-induced ethylene synthesis by ethylene in preclimacteric cantaloupe. Plant Physiol. 69:317-322.

Hung, Y.-C. and S.E. Prussia. 1989. Effect of maturity and storage time on the bruise susceptibility of peaches (cv. Red Globe). Trans. ASAE 32:1377-1382.

Kumar, L. and J.-K. Wang. 1971. Response of papaya fruit to dynamic loading. Trans. ASAE 14:263-267, 272.

MacLeod, R.F., A.A. Kader, and L.L. Morris. 1976. Stimulation of ethylene and carbon dioxide production of mature-green tomatoes by impact bruising. HortScience 11:604-606.

Maxie, E.C., F.G. Mitchell, N.F. Sommer, R.G. Snyder, and H.L. Rae. 1974. Effect of elevated temperature on ripening of 'Bartlett' pear, Pyrus communis L. J. Amer. Soc. Hort. Sci. 99:344-349.

McGlasson, W.B. and H.K. Pratt. 1964. Effects of wounding on respiration and ethylene production by cantaloupe fruit tissue. Plant Physiol. $39: 128-132$
Paull, R.E. and N.J. Chen. 1989. Waxing and plastic wraps influence water loss from papaya fruit during storage and ripening. J. Amer. Soc. Hort. Sci. 114:937-942.

Paull, R.E. and N.J. Chen. 1990. Heat shock response in field-grown, ripening papaya fruit. J. Amer. Soc. Hort. Sci. 115:623-631.

Robitaille, H.A. and J. Janick. 1973. Ethylene production and bruise injury in apples. J. Amer. Soc. Hort. Sci. 98:411-413.

Roudot, A.-C., F. Duprat, and C. Wenian. 1991. Modelling the response of apples to loads. J. Agr. Eng. Res. 48:249-259.

Sanxter, S.S. 1989. Ontogeny and senescence of photosynthetic activity in the exocarp of Carica papaya L. MS Thesis. Univ. of Hawaii, Honolulu.

Skelton, G.S. 1969. Development of proteolytic enzymes in growing papaya fruit. Phytochemistry 8:57-60.

Souza, R.A. 1991. Papaya: Production, marketing, income and industry review. Hawaii Papaya Industry Assn. 27th Annu. Conv., 28 June 1991, Hilo.

Timm, E.J. and G.K. Brown. 1989. Handling impact assessment for papaya. USDA/ARS and Agr. Eng. Dept., Michigan State Univ., East Lansing. in cooperation with the Univ. of Hawaii. 17-18 Sept. 1989. Internal rpt.

Timm, E.J. and G.K. Brown. 1991. Impacts recorded on avocado, papaya and pineapple packing lines. Amer. Soc. Agr. Eng., St. Joseph, Mich. ASAE Paper No. 90-6007.

Wade, N.L. and J.M. Bain. 1980. Physiological and anatomical studies of surface pitting of sweet cherry fruit in relation to bruising, chemical treatments and storage conditions. J. Hort. Sci. 55:375-384.

Wang, J.-K. and H.-S. Chang. 1970. Mechanical properties of papaya and their dependence on maturity. Trans. ASAE 13:369-371.

Zohadie, M. 1982. Elasticity of Malaysian papaya as a design criterion for prevention of damage during transportation. Pertanika 5:178-183. 